\title{
Management of syncope in the emergency department based on risk stratification
}

\author{
Matthew James Reed \\ Emergency Medicine Research Group Edinburgh (EMERGE), Department of Emergency Medicine, Royal \\ Infirmary of Edinburgh; Acute Care Interdisciplinary Research Group, Usher Institute of Population Health \\ Sciences and Informatics, College of Medicine and Veterinary Medicine, University of Edinburgh, Edinburgh, UK
}

\begin{abstract}
This article, based on the 2018 European Society of Cardiology syncope guidelines, highlights the key features of the management of syncope in the Emergency Department (ED) based on risk stratification. Firstly Transient Loss of Consciousness of a syncopal nature should be established. Secondly the treating clinician should ask whether syncope is the presenting feature of an obvious acute disease; if so, treatment and management should follow the guidelines of the specific complaint. If there is no obvious underlying cause, the treating clinician should assess the risk of a serious outcome aided by a risk stratification approach using history, past medical history, examination and ECG. Patients with low-risk characteristics are more likely to have reflex, situational or orthostatic syncope with generally an excellent prognosis and should likely be able to be discharged from the ED with education. Patients with high-risk characteristics are more likely to have cardiac syncope requiring urgent investigation and likely admission but alternatively may be able to be observed in an Observation or Syncope Unit. Patients with neither high nor low-risk features can probably be safely managed in an outpatient setting; there is evi-
\end{abstract}

Correspondence: Matthew James Reed, Emergency Medicine Research Group Edinburgh (EMERGE), Department of Emergency Medicine, Royal Infirmary of Edinburgh, 51 Little France Crescent, Edinburgh, EH16 4SA, UK.

Tel.: 0131.242.1448.

E-mail: matthew.reed@nhslothian.scot.nhs.uk

Key words: Syncope; Emergency department; Transient loss of consciousness; Risk stratification.

Acknowledgements: this article is based on the new 2018 European Society of Cardiology Guidelines for the diagnosis and management of syncope.

Conflict of interest: the author is a member of the European Society of Cardiology 2018 syncope taskforce.

Funding: none.

Received for publication: 20 March 2018.

Revision received: 3 April 2018.

Accepted for publication: 6 April 2018.

This work is licensed under a Creative Commons Attribution 4.0 License (by-nc 4.0).

(C) Copyright M.J. Reed, 2018

Licensee PAGEPress, Italy

Emergency Care Journal 2018; 14:7430

doi:10.4081/ecj.2018.7430 dence that management in an ED observation unit and/or fast track to a syncope clinic is beneficial. Risk stratification scores and clinical decision rules are yet to prove useful. There is little evidence that hospital admission in unexplained syncope is useful and novel organisational approaches such as ED observation units and syncope in- and outpatient units offer safe and effective alternatives to admission.

\section{Introduction}

This article, based on the new 2018 European Society of Cardiology Guidelines for the diagnosis and management of syncope highlights the key features of the management of syncope in the Emergency Department (ED). ${ }^{1}$

\section{Importance of satisfactory emergency department syncope management}

This is an important topic; syncope is a common presentation to EDs and there are problems with current management. These include the lack of high quality evidence based strategies to detect patients at high risk of short-term adverse events and those of longterm adverse outcome, the high admission rate and the low incidence of short-term adverse events. Challenges that can contribute to unsatisfactory practice include the lack of specialist syncope experts and specialist syncope clinics in many hospitals, the lack of a clear speciality leading the field (cardiology, internal medicine and geriatric medicine specialties are among the commonest to lead care in most hospitals), differences in the speciality leading care in the ED (emergency medicine is the commonest to lead care in most EDs however in some countries where it is less developed, internal or geriatric medicine maybe the first to see syncope patients in the ED), differences in the time that patients are allowed to spend in the ED before they must be admitted to a hospital bed (ranging from 4 hours in the United Kingdom to over 24 hours in others), differences in diagnostic pathways within and between hospitals, and finally difficulties disseminating and teaching best practice due to many of the above issues.

\section{Diagnosis and definition of syncope}

As discussed at the SYNERGI (SYNcope Expert Research Group International) ${ }^{2}$ First International Workshop on Syncope Risk Stratification in the ED in Gargnano in 2013, ${ }^{3}$ diagnosing Transient Loss of Consciousness (T-LOC) as being of syncopal origin (i.e. due to cerebral hypoperfusion) can be difficult in the ED. A very careful history is needed to differentiate syncope from epilepsy and other non-TLOC conditions such as pre-syncope, light-headedness, vertigo, disequilibrium, mechanical and collapse 
(i.e. loss of postural tone). In the absence of witnesses this is often very difficult.

SYNERGI ${ }^{2}$ suggest a pragmatic definition of syncope: a transient loss of consciousness, associated with inability to maintain the postural tone and with immediate spontaneous and complete recovery. Syncope should be associated with at least 1 of the following: i) clinical features suggestive of specific forms of syncope (e.g. vasovagal, orthostatic, cardiac, neurologic); or ii) the absence of clinical features specific for another form of transient loss of consciousness such as epileptic seizure, hypoglycemia, or trauma. ${ }^{3}$

Other clinical tips here are to: i) Document all presenting symptoms fully; ii) Get any available history from witnesses or paramedics; iii) Examine the ambulance notes for initial observations and review any pre hospital ECG.

Another critical point is to identify and manage patients with pre-syncope. Pre-syncope is the feeling of being about to pass out without actual Loss of Consciousness. Pre-syncope has ordinarily thought to be associated with a better prognosis compared with syncope. However, some recent studies have suggested that patients presenting with pre-syncope are characterized by outcomes that are similar to those observed in patients with syncope. ${ }^{4-6}$

\section{Is there a serious underlying diagnosis?}

Normally the ED clinician can establish the presenting complaint of syncope. It should be noted that depending on geographical considerations, the ED clinician might be an emergency, internal medicine, geriatric or even a neurology clinician. Regardless, the next step is to see whether there is a serious underlying diagnosis or aetiology that can be identified in the ED, especially if this condition is associated with the potential for rapid clinical deterioration (e.g. abdominal aortic aneurysm, upper gastrointestinal bleeding). ${ }^{7,8}$ Once established, subsequent management of the patient presenting with syncope, will focus on treating the underlying cause using any guidelines specific to this condition. Once an underlying diagnosis is made, syncope guidelines are not beneficial. Most non-cardiovascular and some cardiovascular life-threatening underlying conditions are obvious in the ED and in total around $50 \%$ of patients have an underlying diagnosis or aetiology that can be identified in the ED. ${ }^{9}$

\section{What is the risk of a serious outcome?}

When the cause of syncope remains uncertain after initial evaluation by a clinician in the ED, the next step is to assess the risk of a serious outcome, essentially the risk of a future major cardiovascular event or of sudden cardiac death, and to use this risk profile to guide the patient's subsequent management and disposition. ${ }^{10}$

Risk stratification is important, for two reasons. Firstly it is important to recognise low-risk patients who are more likely to have reflex, situational or orthostatic syncope with generally an excellent prognosis, ${ }^{11}$ although postural syncope may be associated with slightly higher risk poor outcome owing to the severity of comorbidities compared with the general population. ${ }^{12}$ These lowrisk patients should be able to be discharged from the ED and most should be able to be managed with adequate patient education and counselling that can be started in the ED. Some patients with frequent or severe (causing injury) episodes may require further investigation (e.g. to uncover whether syncope is cardio inhibitory versus vasodepressor) and/or specific treatment (e.g. pacemaker insertion, commencement or withdrawal of drug treatment). Secondly it is important to recognise patients more likely to have cardiac syncope who will require urgent investigation. This may require admission depending on available services, which are likely to be hospital dependent. Structural heart disease ${ }^{13-18}$ and primary electrical disease ${ }^{19}$ are major risk factors for sudden cardiac death and overall mortality in patients with syncope.

\section{Risk stratification}

The 2018 European Society of Cardiology (ESC) Guidelines for the diagnosis and management of syncope ${ }^{1}$ recommend that ED risk stratification should be undertaken using the following risk stratification system using high-risk features (suggestive of a serious condition) and low-risk features (suggestive a benign condition) in patients with syncope at initial evaluation in the ED.

\section{Syncopal event}

\section{Low risk}

i) Associated with prodrome typical of reflex syncope (e.g. light-headedness, feeling of warmth, sweating, nausea, vomiting); ii) After sudden unexpected unpleasant sight, sound, smell, or pain; iii) After prolonged standing or crowded, hot places; iv) During a meal or postprandial; v) Triggered by cough, defaecation, or micturition; vi) With head rotation or pressure on carotid sinus (e.g. tumour, shaving, tight collars); vii) Standing from supine/sitting position.

\section{High risk (red flag)}

Major: i) New onset of chest discomfort, breathlessness, abdominal pain, or headache; ii) Syncope during exertion or when supine; iii) Sudden onset palpitation immediately followed by syncope.

Minor (high risk only if associated with structural heart disease or abnormal Electrocardiogram; ECG): i) No warning symptoms or short $(<10 \mathrm{~s})$ prodrome; ii) Family history of Sudden Cardiac Death (SCD) at young age; iii) Syncope in the sitting position.

\section{Past medical history}

\section{Low risk}

i) Long history (years) of recurrent syncope with low-risk features with the same characteristics of the current episode; ii) Absence of structural heart disease.

\section{High risk (red flag)}

Major: Severe structural or coronary artery disease (heart failure, low left ventricular ejection fraction; LVEF or previous myocardial infarction).

\section{Physical examination}

\section{Low risk}

Normal examination.

\section{High risk (red flag)}

i) Unexplained systolic blood pressure (BP) in the ED $<90$ $\mathrm{mmHg}$; ii) Suggestion of gastrointestinal bleed on rectal examination; iii) Persistent bradycardia ( $<40$ beats per minute; bpm) in awake state and in absence of physical training; iv) Undiagnosed systolic murmur.

\section{Electrocardiography}

Low risk

Normal ECG.

High risk (red flag)

Major: i) ECG changes consistent with acute ischaemia; ii) 
Mobitz II second- and third-degree atrio-ventricular (AV) block; iii) Slow Atrial Fibrillation (AF) $(<40 \mathrm{bpm})$; iv) Persistent sinus bradycardia $(<40 \mathrm{bpm})$, or repetitive sinoatrial block or sinus pauses $>3$ seconds in awake state and in absence of physical training; v) Bundle branch block, intraventricular conduction disturbance, ventricular hypertrophy, or $\mathrm{Q}$ waves consistent with ischaemic heart disease or cardiomyopathy; vi) Sustained and non-sustained Ventricular Tachycardia (VT); vii) Dysfunction of an implantable cardiac device (pacemaker or implantable cardioverter defibrillator; ICD); viii) ST-segment elevation with type 1 morphology in leads V1-V3 (Brugada pattern); ix) QTc $>460 \mathrm{~ms}$ in repeated 12lead ECGs indicating long QT syndrome (LQTS).

Minor (high risk only if history consistent with arrhythmic syncope): i) Mobitz I second-degree AV block and $1^{\circ}$ degree AV block with markedly prolonged PR interval; ii) Asymptomatic inappropriate mild sinus bradycardia (40-50 bpm), or slow AF (4050 bpm); iii) Paroxysmal supraventricular tachycardia (SVT) or atrial fibrillation; iv) Pre-excited QRS complex; v) Short QTc interval ( $\leq 340 \mathrm{~ms}$ ); vi) Atypical Brugada patterns; vii) Negative T waves in right precordial leads, epsilon waves suggestive of arrhythmogenic right ventricular cardiomyopathy.

Once ED risk stratification has been undertaken the ESC ED risk stratification flowchart shown in Figure 1 should be used to determine the subsequent patient's management. ${ }^{1}$

\section{Patients with low-risk features}

A patient with only low-risk characteristics and without any high-risk characteristics can be classified as low risk and can be safely discharged from the ED. These patients do not need further diagnostic tests in the ED and their likely diagnosis is reflex, situational, or orthostatic syncope. These patients may benefit from reassurance, education and counselling, which the patient's General Practitioner can provide. They may also benefit from an advice sheet on low-risk syncope. Low-risk patients may still require further examination or investigation, and possibly admission to hospital in the event of them having associated injury or social or welfare reasons meaning they are not able to be discharged home.

Current use of hospitalization for patients with low-risk features is both inefficient and inconsistent; these patients can be safely discharged home from the ED. Avoiding admission of these patients may significantly reduce hospital admissions, thus cutting costs and decreasing adverse outcomes associated with unnecessary hospitalization.

\section{Patients with high-risk features}

Patients with any high-risk features should be classified as high risk and should not be discharged from the ED as they require a timely and thorough diagnostic approach and may need urgent treatment. This is likely to mean an admission to hospital unless patients can access urgent advanced investigation such as echocardiography, ECG monitoring, specialized cardiovascular tests and review from an expert in syncope during either a prolonged stay in the ED or in a syncope clinical decision/investigation unit. These

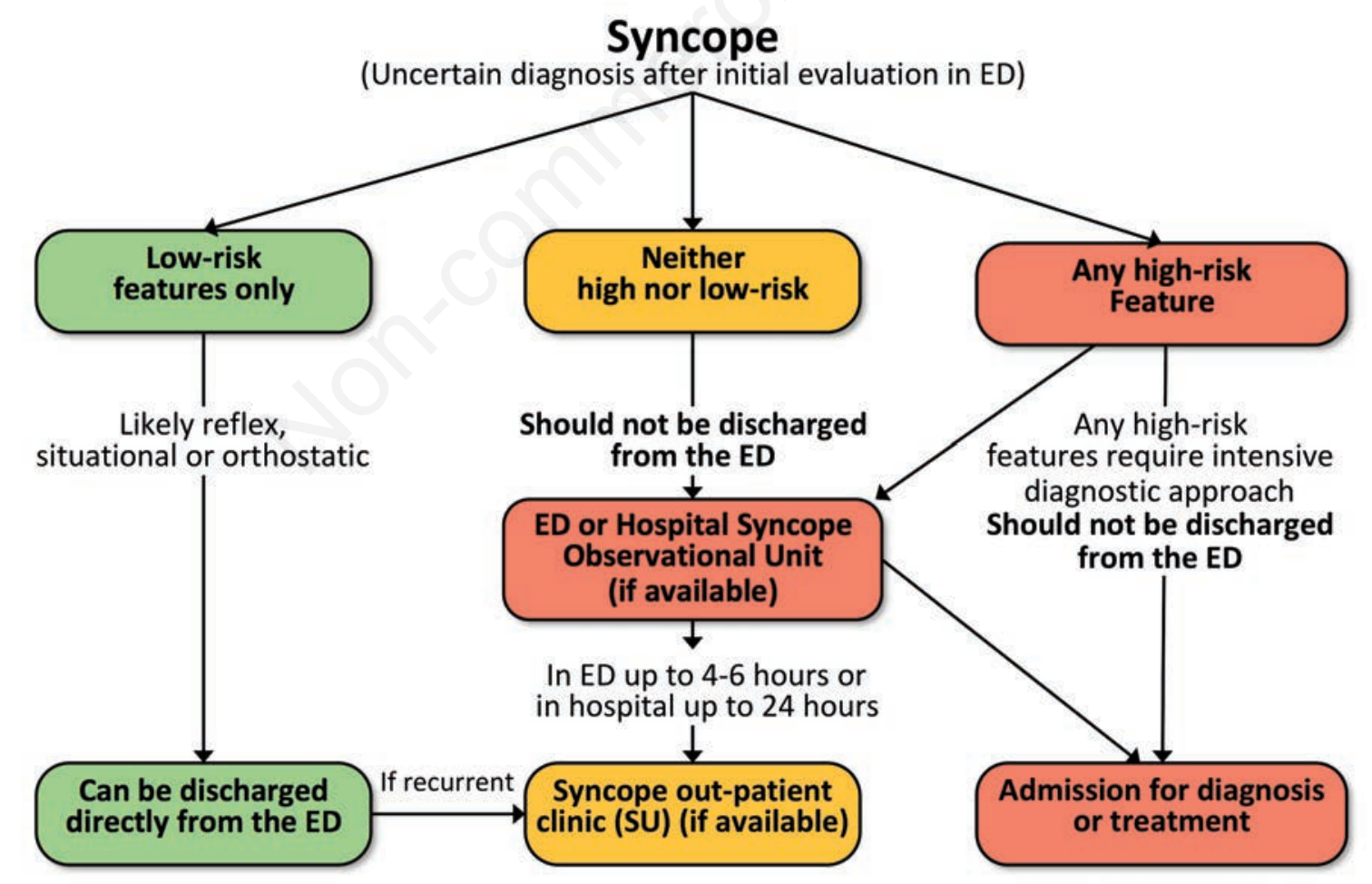

Figure 1. Emergency department risk stratification flowchart to determine syncope patient management of syncope. SU, syncope unit. Reproduced from Brignole M, et al. 2018 ESC Guidelines for the diagnosis and management of syncope. European Heart Journal (2018) 00, 1-69, doi:10.1093/eurheartj/ehy037. Reproduced by permission of Oxford University Press on behalf of the European Society of Cardiology. (c) European Society of Cardiology 2018. All rights reserved. This figure is not included under the Open Access license of this Publication. 
patients should be monitored (although it is unclear for how long this should be, most experts suggest from 4 to 24 hours) in a setting where resuscitation can be performed in case of deterioration. ${ }^{20,21}$

The ability for patients to access an ED observation unit or syncope clinical decision unit will be dependent on geographical and hospital considerations. Not all countries have Emergency Departments. In some countries, patients have to be discharged from the ED or admitted to hospital within a certain time of their attendance to the $\mathrm{ED}$ (e.g. in the UK, this period is 4 hours). Despite them having being many advantages, many hospitals do not currently have observation/clinical decision units. If this is the case, until such a time when these services are available, the highrisk syncope patient will require admission to hospital. Patients with high-risk features should not be discharged home without follow-up from the ED, as they require an intensive diagnostic approach.

\section{Patients with intermediate-risk features}

There will be patients that have neither high nor low-risk features. Dealing with these intermediate-risk patients is difficult. Many will require expert syncope opinion and this can probably be safely managed in an outpatient setting. ${ }^{22}$ There is evidence that management in an ED observation unit and/or fast track to a syncope clinic is beneficial. Shen et al. ${ }^{23}$ showed that a designated syncope unit in the ED, where patients could stay for up to 6 hours, significantly improved diagnostic yield in the ED, and reduced hospital admission and total length of hospital stay without affecting recurrent syncope and all-cause mortality among intermediaterisk patients. Patients underwent continuous cardiac monitoring, an hourly vital sign check, echocardiography (in patients with abnormal cardiovascular examination findings or an abnormal ECG), tilt table testing, and specialist consultation if indicated. Sun et al. ${ }^{23}$ showed that an ED observation syncope protocol reduced admission rates, length of hospitalization, and index hospital costs, with no difference in the rates of safety events, quality of life, or patient satisfaction. Patients in this study could stay for up to 24 hours in an ED observation unit, receiving continuous cardiac monitoring for at least 12 hours, interval cardiac troponin tests, echocardiograms for patients with a cardiac murmur on chest auscultation, and additional testing at the ED clinician's discretion.

\section{Requirements of an emergency department syn- cope observation unit}

An ED syncope observation unit should have the following tests, equipment, and characteristics: ECG and BP monitoring, standing test facilities, carotid sinus massage capability, echocardiogram, blood tests, and availability of consultation by a syncope expert and neurologists, cardiologists, geriatricians, and psychiatrists where required.

\section{Does the patient need to be admitted to hospital?}

The final question that the treating clinician needs to ask is whether the patient should be admitted to hospital. Approximately $50 \%$ of patients who present to the ED for syncope are admitted to hospital, although the rate of admissions varies between $12 \%$ and $86 \%$ (Table 1). ${ }^{9,15,24-34}$ The adoption of clinical decision rules and standard protocols has not changed the rate of hospital admission significantly and many are unnecessary. ${ }^{35}$ Among the patients who present to the ED with syncope, only $0.8 \%$ die, $6.9 \%$ have a nonfatal severe outcome whilst in the ED, and another $3.6 \%$ have a serious outcome in the next 7-30 days (Table 1). Therefore, whereas it is crucial to identify these high-risk patients to ensure early, rapid, and intensive investigation, the rate of post-ED serious outcome is actually quite low and not all patients at high risk need to be admitted.

Some high-risk patients may inevitably require admission to hospital in the event of severe coexisting disease, injury caused by

Table 1. Admission rate and composite estimate of short-term (7-30 days) outcomes of patients presenting in emergency department with Transient Loss of Consciousness (T-LOC). Reproduced from Brignole M, et al. 2018 ESC Guidelines for the diagnosis and management of syncope. European Heart Journal (2018) 00, 1-69, doi:10.1093/eurheartj/ehy037. Reproduced by permission of Oxford University Press on behalf of the European Society of Cardiology. (c) European Society of Cardiology 2018. All rights reserved. This table is not included under the Open Access license of this Publication.

\begin{tabular}{|c|c|c|c|c|c|c|}
\hline Author/year/country & $\begin{array}{l}\text { Patients } \\
\text { with } \\
\text { T-LOC }\end{array}$ & $\begin{array}{l}\text { Number } \\
\text { admitted }\end{array}$ & $\begin{array}{l}\text { 7-30 day } \\
\text { Death }\end{array}$ & $\begin{array}{l}\text { 7-30 day non-fatal } \\
\text { severe outcome }\end{array}$ & $\begin{array}{l}\text { 7-30 day non-fatal } \\
\text { severe outcome } \\
\text { identified in the ED }\end{array}$ & $\begin{array}{l}\text { 7-30 day non-fatal } \\
\text { severe outcome }{ }^{\mathrm{a}} \text { identified } \\
\text { after initial visit }\end{array}$ \\
\hline Costantino, 2008, Italy 25 & 676 & $218(32 \%)$ & $5(0.7 \%)$ & $36(5.3 \%)$ & $\mathrm{n} / \mathrm{a}$ & $\mathrm{n} / \mathrm{a}$ \\
\hline Brignole, 2006, Italy ${ }^{26}$ & 465 & $178(38 \%)$ & $6(1.3 \%)$ & $\mathrm{n} / \mathrm{a}$ & $\mathrm{n} / \mathrm{a}$ & $\mathrm{n} / \mathrm{a}$ \\
\hline Reed, 2010, UK ${ }^{9}$ & 1100 & $541(49 \%)$ & $17(1.5 \%)$ & $79(7.2 \%)$ & n/a & $\mathrm{n} / \mathrm{a}$ \\
\hline Ungar, 2015, Italy ${ }^{34}$ & 295 & $92(31 \%)$ & $1(0.3 \%)$ & $\mathrm{n} / \mathrm{a}$ & $\mathrm{n} / \mathrm{a}$ & $21(7.1 \%)$ \\
\hline Birnbaum, 2008, US ${ }^{27}$ & 713 & $613(86 \%)$ & $4(0.6 \%)$ & $57(8.0 \%)$ & $32(4.5 \%)$ & $25(3.5 \%)$ \\
\hline Grossman, 2007, US²8 & 293 & $201(69 \%)$ & $7(2.4 \%)$ & $68(23 \%)$ & $56(19 \%)$ & $12(4.1 \%)$ \\
\hline Quinn, 2004, US'29 & 684 & $376(55 \%)$ & $5(0.7 \%)$ & $79(11.5 \%)$ & $\mathrm{n} / \mathrm{a}$ & $\mathrm{n} / \mathrm{a}$ \\
\hline Quinn, 2006, US ${ }^{15}$ & 760 & 448 (59\%) & $3(0.4 \%)$ & $108(14.2 \%)$ & $54(7.1 \%)$ & $54(7.1 \%)$ \\
\hline Schladenhaufen, 2008, US 30 & 517 & $312(60 \%)$ & $5(1.0 \%)$ & $98(19 \%)$ & $80(15.5 \%)$ & $18(3.4 \%)$ \\
\hline Sun, 2007, US ${ }^{31}$ & 477 & $277(58 \%)$ & $\mathrm{n} / \mathrm{a}$ & $56(11.7 \%)$ & $40(8.6 \%)$ & $16(3.4 \%)$ \\
\hline Daccarett, 2011, US ${ }^{32}$ & 254 & $118(46 \%)$ & $1(0.4 \%)$ & $15(5.9 \%)$ & $8(3.1 \%)$ & $7(2.8 \%)$ \\
\hline Thiruganasambanda-moorthy, 2014, CAN ${ }^{33}$ & 33305 & $62(12 \%)$ & $5(1.0 \%)$ & $49(9.7 \%)$ & $22(4.4 \%)$ & $27(5.3 \%)$ \\
\hline Thiruganasambanda-moorthy, 2015, CAN 34 & $343662^{\mathrm{b}}$ & $474(13 \%)$ & $31(0.9 \%)$ & $345(10.3 \%)$ & $225(6.7 \%)$ & $120(3.6 \%)$ \\
\hline Median (IQR) & & $49 \%(32-59)$ & $0.8 \%(0.6-1.1)$ & $10.3 \%(7.6-13.0)$ & $6.9 \%(4.5-10.3)$ & $3.6 \%(3.4-5.3)$ \\
\hline
\end{tabular}

${ }^{a}$ Nonfatal severe outcomes generally are defined as a significant new diagnosis, a clinical deterioration, serious injury with recurrence, or a significant therapeutic intervention; 33365 patients had 30 day follow-up. 
the syncopal event, need of further urgent evaluation and treatment (e.g. ECG monitoring, echocardiography, stress test, angiography) if it cannot be achieved any another way (i.e. observation unit) and if syncope related treatment is required. The implementation of novel care pathways and organizational approaches such as ED observation units and syncope in- and outpatient units do offer safe and effective alternatives to admission in all other patients with high-risk features (e.g. syncope during exertion, palpitations at the time of syncope, suspected device malfunction or inappropriate intervention). Integrated models comprising a short stay in the ED under observation coupled with fast track to a syncope unit have been shown to reduce admission rates to $29 \% .{ }^{36}$ Among patients not admitted, $20 \%$ were discharged after a short observation in the ED, $20 \%$ were fast-tracked to the syncope unit, and $31 \%$ were discharged directly from the ED.

\section{Clinical decision rules}

There are several ED syncope risk-stratification tools and Clinical Decision Rules (CDRs) that aim to stratify patients with syncope in the ED based on medical history, examination and ECG findings into those with a high or low risk of developing both short (7 and 30 day) and long term (1 year) serious outcomes. ${ }^{9,11,13,21,29}$

Currently available clinical decision rules are not used widely in EDs, as they have not shown better sensitivity, specificity, or prognostic yield compared with clinical judgment in predicting short-term serious outcomes after syncope. ${ }^{37}$ They should not be used alone to perform risk stratification in the ED.

The failure of CDRs is likely because they attempt to predict prognosis on the basis of presenting complaint and attempt to predict multiple heterogeneous outcomes. CDRs struggle to identify rarer treatable conditions; most CDRs would correctly predict a worse but less modifiable 30 day outcome for an 80 year old male with a history of cardiovascular disease and a non specific abnormal ECG presenting with reflex syncope, compared to a 25 year old female with exertional syncope caused by treatable congenital long QT syndrome. Clinical decision rules can predict poor outcomes, but most syncope deaths and many poor outcomes are associated with underlying illness rather than syncope per se, ${ }^{38}$ particularly in the long term. ${ }^{25}$

\section{Biomarkers}

Although there is increasing interest in the use of biomarkers such as troponins and brain natriuretic peptides for ED syncope risk stratification, these cannot be recommended for routine care at present. ${ }^{39-43}$

Whilst this article assumes that most patients will be seen in an ED setting, it is acknowledged that some individuals with a serious underlying diagnosis may present to General/Family Practice where some diagnostic resources such as ECG may not be available. The guidance discussed may be used to determine the need for urgent referral to the ED or outpatient clinic. However, patients who attend the ED are likely to represent the more extreme end of the syncope severity spectrum and the majority of patients (especially those of younger age) who either do not seek medical attention, or who visit their GP are more likely to have had an episode of reflex syncope. ${ }^{44-47}$

\section{Conclusions}

The 2018 ESC syncope guidelines have introduced some changes in ED management of patient with syncope. For the first time, the ESC guidelines include a whole section dedicated to the management of the patient with syncope who presents to the ED. The guidelines advocate a risk stratification approach introducing the concept and definitions of low and high-risk patients and low and high-risk features. The guidelines also advocate more widespread use of ED observation and syncope units, and specialist syncope outpatient clinics to reduce admissions to hospital. The guidelines discuss the ideal structure (staff, equipment, and procedures), assessment strategies, and access and quality indicators of such units. Finally the guidelines discuss the limited usefulness of risk stratification and clinical decision scores.

\section{References}

1. Brignole M, Moya A, Deharo J-C, et al. 2018 ESC Guidelines for the diagnosis and management of syncope. Eur Heart $\mathrm{J}$ 2018;00:1-69.

2. SYNERGI, SYNcope Expert Research Group International. Available from: https://twitter.com/SyncopeGroup. Accessed: April 2018.

3. Sun BC, Costantino G, Barbic F, et al. Priorities for emergency department syncope research. Ann Emerg Med 2014;64:64955 .

4. Thiruganasambandamoorthy V, Stiell IG, Wells GA, et al. Outcomes in presyncope patients: a prospective cohort study. Ann Emerg Med 2015;65:268-76.e266.

5. Greve Y, Geier F, Popp S, et al. The prevalence and prognostic significance of near syncope and syncope: a prospective study of 395 cases in an emergency department (the SPEED study). Dtsch Arztebl Int 2014;111:197-204.

6. Krahn AD, Klein GJ, Yee R, REVEAL Investigators. Predictive value of presyncope in patients monitored for assessment of syncope. Am Heart J 2001;141:817-21.

7. Crane SD. Risk stratification of patients with syncope in an accident and emergency department. Emerg Med J 2002;19: 23-7.

8. Sheldon R, Rose S, Ritchie D, et al. Historical criteria that distinguish syncope from seizures. J Am Coll Cardiol 2002;40:142-8.

9. Reed MJ, Newby DE, Coull AJ, et al. The ROSE (risk stratification of syncope in the emergency department) study. J Am Coll Cardiol 2010;55:713-21.

10. Huff JS, Decker WW, Quinn JV, et al. American College of Emergency Physicians. Clinical policy: critical issues in the evaluation and management of adult patients presenting to the emergency department with syncope. Ann Emerg Med 2007;49:431-44.

11. Soteriades ES, Evans JC, Larson MG, et al. Incidence and prognosis of syncope. N Engl J Med 2002;347:878-85.

12. Ricci F, Fedorowski A, Radico F, et al. Cardiovascular morbidity and mortality related to orthostatic hypotension: a metaanalysis of prospective observational studies. Eur Heart J 2015;36: 1609-17.

13. Colivicchi F, Ammirati F, Melina D, OESIL (Osservatorio Epidemiologico sulla Sincope nel Lazio) Study Investigators. Development and prospective validation of a risk stratification system for patients with syncope in the emergency department: the OESIL risk score. Eur Heart J 2003;24: 811-9.

14. Del Rosso A, Ungar A, Maggi R, et al. Clinical predictors of cardiac syncope at initial evaluation in patients referred urgently to a general hospital: the EGSYS score. Heart 2008;94:1620-6.

15. Quinn J, McDermott D, Stiell I, et al. Prospective validation of the San Francisco Syncope Rule to predict patients with serious outcomes. Ann Emerg Med 2006;47:448-54.

16. Olshansky B, Poole JE, Johnson G, SCD-HeFT Investigators. 
Syncope predicts the outcome of cardiomyopathy patients: analysis of the SCD-HeFT study. J Am Coll Cardiol 2008;51:1277-82.

17. Sarasin FP, Hanusa BH, Perneger T, et al. A risk score to predict arrhythmias in patients with unexplained syncope. Acad Emerg Med 2003;10:1312-7.

18. Middlekauff HR, Stevenson WG, Stevenson LW, Saxon LA. Syncope in advanced heart failure: high risk of sudden death regardless of origin of syncope. J Am Coll Cardiol 1993;21:110-6.

19. Priori SG, Blomstrom-Lundqvist C, Mazzanti A, et al. 2015 ESC Guidelines for the management of patients with ventricular arrhythmias and the prevention of sudden cardiac death: the task force for the management of patients with ventricular arrhythmias and the prevention of sudden cardiac death of the European Society of Cardiology (ESC). Endorsed by: Association for European Paediatric and Congenital Cardiology (AEPC). Eur Heart J 2015;36:2793-867.

20. Casagranda I, Brignole M, Cencetti S, et al. Management of transient loss of consciousness of suspected syncopal cause, after the initial evaluation in the Emergency Department. Emerg Care J 2016;12:25-7.

21. Costantino G, Sun BC, Barbic F, et al. Syncope clinical management in the emergency department: a consensus from the first international workshop on syncope risk stratification in the emergency department. Eur Heart J 2016;37:1493-8.

22. Kenny RA, Brignole M, Dan GA, et al. Syncope Unit: rationale and requirement-the European Heart Rhythm Association position statement endorsed by the Heart Rhythm Society. Europace 2015;17:1325-40.

23. Shen WK, Decker WW, Smars PA, et al. Syncope Evaluation in the Emergency Department Study (SEEDS): a multidisciplinary approach to syncope management. Circulation 2004; 110:3636-45.

24. Sun BC, McCreath H, Liang LJ, et al. Randomized clinical trial of an emergency department observation syncope protocol versus routine inpatient admission. Ann Emerg Med 2014;64:167-75.

25. Costantino G, Perego F, Dipaola F, et al. Short- and long-term prognosis of syncope, risk factors, and role of hospital admission: results from the STePS (Short-Term Prognosis of Syncope) study. J Am Coll Cardiol 2008;51:276-83.

26. Brignole M, Menozzi C, Bartoletti A, et al. A new management of syncope: prospective systematic guideline-based evaluation of patients referred urgently to general hospitals. Eur Heart J 2006; 27:76-82.

27. Birnbaum A, Esses D, Bijur P, et al. Failure to validate the San Francisco Syncope Rule in an independent emergencydepartment population. Ann Emerg Med 2008;52:151-9.

28. Grossman SA, Fischer C, Lipsitz LA, et al. Predicting adverse outcomes insyncope. J Emerg Med 2007;33:233-9.

29. Quinn JV, Stiell IG, McDermott DA, et al. Derivation of the San Francisco Syncope Rule to predict patients withshort-term serious outcomes. Ann Emerg Med 2004;43:224-32.

30. Schladenhaufen R, Feilinger S, Pollack M, et al. Application of San Francisco Syncope Rule in elderly ED patients. Am J Emerg Med 2008;26:773-8.
31. Sun BC, Mangione CM, Merchant G, et al. External validation of the San Francisco Syncope Rule. Ann Emerg Med 2007;49:420-7.e1-4.

32. Daccarett M, Jetter TL, Wasmund SL, et al. Syncope in the emergency department: comparison of standardized admission criteria with clinical practice. Europace 2011;13:1632-8.

33. Thiruganasambandamoorthy V, Hess EP, Turko E, et al. Outcomes in Canadian Emergency Department Syncope Patients - are we doing a good job? J Emerg Med 2013;44:321-8.

34. Thiruganasambandamoorthy V, Steill IG, Sivilotti ML, et al. Emergency department management of syncope: need for standardization and improved risk stratification. Intern Emerg Med 2015;10:619-27.

35. Sheldon RS, Morillo CA, Krahn AD, et al. Standardized approaches to the investigation of syncope: Canadian Cardiovascular Society position paper. Can J Cardiol 2011;27:246-53.

36. Ungar A, Tesi F, Chisciotti VM, et al. Assessment of a structured management pathway for patients referred to the Emergency Department for syncope: results in a tertiary hospital. Europace 2016;18:457-62.

37. Costantino G, Casazza G, Reed M, et al. Syncope risk stratification tools vs clinical judgment: an individual patient data meta-analysis. Am J Med 2014;127: 1126.e1113-1125.

38. Kapoor WN, Peterson J, Wieand HS, Karpf M. Diagnostic and prognostic implications of recurrences in patients with syncope. Am J Med 1987;83:700-8.

39. Costantino G, Solbiati M, Casazza G, et al. Usefulness of Nterminal pro-B-type natriuretic Peptide increase as a marker for cardiac arrhythmia in patients with syncope. Am J Cardiol 2014;113:98-102.

40. Reed MJ, Mills NL, Weir CJ. Sensitive troponin assay predicts outcome in syncope. Emerg Med J 2012;29:1001-3.

41. Thiruganasambandamoorthy V, Ramaekers R, Rahman MO, et al. Prognostic value of cardiac biomarkers in the risk-stratification of syncope: a systematic review. Int Emerg Med 2015 [Ahead of print]. doi: 10.1007/s11739-015-1318-1.

42. Fedorowski A, Burri P, Struck J, et al. Novel cardiovascular biomarkers in unexplained syncopal attacks: the SYSTEMA cohort. J Intern Med 2013;273: 359-67.

43. Reed MJ, Newby DE, Coull AJ, et al. Role of brain natriuretic peptide (BNP) in risk stratification of adult syncope. Emerg Med J 2007;24:769-73.

44. Soteriades ES, Evans JC, Larson MG, et al. Incidence and prognosis of syncope. N Engl J Med 2002;347:878-85.

45. Serletis A, Rose S, Sheldon AG, Sheldon RS. Vasovagal syncope in medical students and their first-degree relatives. Eur Heart J 2006;27:1965-70.

46. Colman N, Nahm K, Ganzeboom KS, et al. Epidemiology of reflex syncope. Clin Auton Res 2004;14 Suppl 1:i9-i17.

47. Ganzeboom KS, Mairuhu G, Reitsma J, et al. Lifetime cumulative incidence of syncope in the general population: a study of 549 Dutch subjects aged 35-60 years. J Cardiovasc Electrophysiol 2006;17:1172-6. 